\title{
BEHAVIOUR OF GGBS AND NANO-SILICA ON STRENGTH PROPERTIES OF
}

\section{CONCRETE}

\author{
Ramesh.N ${ }^{1}$, Eramma.H. ${ }^{2}$ \\ ${ }^{1}$ U.B.D.T. College of Engineering, Davanagere, Karnataka \\ ${ }^{2}$ U.B.D.T. College of Engineering, Davanagere, Karnataka
}

\begin{abstract}
Due to the persistent and continuous demands made on concrete to meet the various difficult requirements, extensive and wide spread research work is being carried out in the area of concrete technology. Nano Technology being applied to concrete includes the use of nano materials like nano silica, nano fibers etc. By adding the nano materials smart concrete composites with superior properties can be produced. In the present experimental investigation is to find the influence of Nano-Silica (NS) and GGBS on strength properties of concrete. GGBS and Nano-Silica are used as partial replacement of cement. In the present experimental investigation the cement is partially replaced by 10\%, 20\% and 30\% of GGBS and Nano-Silica 1\%, 2\% and 3\% by weight. The influence of combined application of GGBS and Nano-Silica on compressive strength, split tensile strength, flexural strength of M30 grade of concrete is investigated. The test results of concrete prepared using the different proportions of GGBS and Nano-Silica are compared with that of conventional concrete. The variation of different test results of concrete prepared with various proportions of GGBS and Nano-Silica indicates the same trend. Based on the test results, it can be observed that concrete prepared with $30 \%$ GGBS and 2\% Nano-Silica combination possesses improved properties and also better microstructural properties compared to that of conventional concrete. The increase in the various strength characteristics of concrete prepared using GGBS and Nano-Silica can be attributed to the effective particle packing and the also the availability of additional binder in the presence of GGBS and Nano-Silica.
\end{abstract}

Keywords: Nano-Silica(NS),GGBS, Compressive Strength, Split Tensile Strength, Flexural Strength Mechanical Properties

\section{INTRODUCTION}

Concrete is one of the most widely used construction material and its usage is next only to water. Concrete is a popular choice among all the building materials because of its ease with which it can be locally produced, versatility, economic, wide ranging performance, suitability, durability and applicability. Annual global production of concrete is about 5 billion cubic yards and is increased by $10 \%$ each year. Global production of concrete is approximately estimated about 25 billion tonnes every year. Among which, truck load comprises of 6.4 billion tonnes of concrete a day and for each person it is estimated over 3.8 tonnes in the world each year.

Recently nano-technology has been introduced in civil Engineering applications. One of the most used nano material is nano-silica(NS). Nano-silica can be usd as an additive to the eco concrete mixtures. In the case of eco concrete mixtures, industrial waste such as blast furnace slag are used as admixtures at certain percentage as replacement of cement. Certain problems such as longer setting time, lower compressive strength, at higher percentage can be overcome by adding nano-silica which improves these properties. GGBS is a byproduct of iron manufacturing industries when used as partial replacement to cement (upto $10 \%-30 \%$ ) has been formed to contribute towards strength increase of concrete in addition to other beneficial properties.

\subsection{Benefits of Using GGBS in Concrete}

\subsubsection{Sustainability}

It has been reported that the manufacture of one tonne of Portland cement would require about 1.5 tones of mineral extractions together with $5000 \mathrm{MJ}$ of energy, and would generate about 0.95 tone of $\mathrm{CO} 2$ equivalent. As GGBS is0a by-product of the iron manufacturing industry, the production of one tone of GGBS would only generate about 0.07 tone of $\mathrm{CO} 2$ equivalent and consume about $1300 \mathrm{MJ}$ of energy According to Higgins (op cit), GGBS scores 0.47 Eco points, whereas Portland cement scores 4.6, which means GGBS would only bring about one-tenth of that of Portland cement in terms of environmental impact.

In China, it has been reported that a GGBS manufacturer in Xi'an produced about 1.2 million tonnes of GGBS in year 2008, which could help to reduce about 1.2 million tones of $\mathrm{CO} 2$ equivalent emissions, 1.10million tonnes of coal consumption and 1.7 million tones of mineral extraction. There are obvious environmental benefits by making full use of the slag (ChinaBiz, 2009).

\subsubsection{Concrete With Improved Durability}

It is generally known that GGBS can improve the durability of a concrete structure by reducing the water permeability, increasing the corrosion resistance and increasing the sulphate resistance. The improved properties can extend the 
service life of structures and reduce the overall maintenance costs. Based on a life cycle prediction model, the service life of a Maryland bridge deck was estimated to have increased from 38 years to 75 years with the use of concrete incorporating $40 \%$ GGBS replacement (Slag Cement Association, 2005).

\subsubsection{Benefits of Nano Silica}

1. Addition of nano silica in concretes and mortars results in more efficient hydration of cement.

2. More strength is developed which helps in reducing the cement requirement.

3. Nano silica improves the micro structure and makes concrete more impermeable and more durable.

4. As it produces a dense concrete, compressive strength is increased.

\subsubsection{Details of the Present Experimental Study}

The present experimental investigation is mainly carried out to find out the influence of nano-Silica on concrete composites consisting of mineral admixtures like GGBS are tried in the present investigation.

\section{LITERATURE REVIEW}

B. Kartikeyan, K. Sumanth (2014)16, investigated the Microstructure analysis and Strength properties of concrete with Nano $\mathrm{SiO} 2$ and mineral admixtures in concrete as a partial replacement of cement and micro structure analysis using Scanning Electron Microscopev(SEM), Chemical composition identification by X-Ray Fluorescent (XRF), Crystalline check for silica using X-Ray Diffraction (XRF) were performed for samples of both un ground and ground micro-silica. Mechanical properties were obtained by performing strength tests for specimens cast with different percentages of ground and un ground micro-silica in partial replacements such as 5\%, $10 \%$ and $15 \%$ by weight of cement. From the results it is understood that cubes cast with $10 \%$ replacement of nano silica for cement by weight are showing better strength performance. J. M. Kaura.et.al., (2014)17, Concluded that Effect of Nanosilica on Mechanical and Micro structural Properties of Cement Mortar. Numbers of specimens were prepared to study the behavior of cement mortar containing nanosilica. The cement replacement by nanosilica of $3 \%$ and $5 \%$ by weight of cement was used. The experimental results show that cement mortars containing nanosilica have higher strength than ordinary Portland cement mortars. The SEM images confirmed the improvement in the microstructure of mortar with nanosilica. Dr. D. V. PrasadaRao, M. Pavan Kumar (2014)19, 0A Study On Influence Of Fly Ash And NanoSilica On Strength Properties Of Concrete cement is partially replaced by $20 \%$ and $30 \%$ of Fly Ash and NanoSilica $1.5 \%, 3 \%$ and $4.5 \%$ by weight.. Using the test results, it can be concluded that with the increase in the percentage of nano-silica the various strength characteristics of concrete increased up to $3 \%$, with further increase in the nano-silica the strength characteristics of concrete are decreased for the given percentages of fly ash possesses improved properties compared to the controlled concrete. Mohammad Reza Zamani Abyaneh.et.al., (2013)15, studied that the concrete produced with Micro-SiO2 and Nano-SiO2 show higher compressive strength than the concrete which only have Micro-SiO20in their mixtures. Specimens with $2 \%$ Nano-SiO2 and 10\% Micro-SiO2 had less water absorption and more electrical resistance by the study of concrete at nano scale has proved that nano silica is much better than silica fume used in conventional concrete. Nano silica possess more pozzolanic nature, it has the capability to react with the free lime during the cement hydration and forms additional C-S-H gel which gives strength, impermeability and durability to concrete. Abdul Wahab, B. Dean Kumar.et.al., (2013)22, Experimental investigation on High Strength Concrete Mixes of M60 and M80 are studied for their mechanical properties. A combination of mineral admixtures like nano silica (nS) and condensed fly ash with OPC is used as replacement to cement in certain proportions and the strength properties are studied.

\section{EXPERIMENTAL INVESTIGATION}

\subsection{Cement}

In the investigation OPC(ultra Tech) 53 grade cement Is used. The cement was tested as oer IS specifications.

\subsubsection{Fine Aggregates}

Locally available river sand was used.

\subsubsection{Coarse Aggregates}

The crushed stone aggregate of maximum size $20 \mathrm{~mm}$ was used. Fine and Coarse aggregates were tested as per the IS Specifications.

\subsubsection{GGBS}

GGBS which is a industrial byproduct of iron manufacturing industries obtained from 'jsw steels' Bellary, Karnataka.

\subsubsection{Nano-Silica(ns)}

$\mathrm{PH}: 13.6$

Specific Gravity:1.08-1.11

Particle Size: $19 \mathrm{~nm}$

The material was obtained from Sisco research Laboratories PVT Ltd Mumbai india.

\subsubsection{Superplasticizer}

Conplat 430 of "vissotrading.co', Bangalore was1used Wherever found necessary in the experimental investigation.

\subsection{Concrete Mix Design}

The mix design procedure adopted to obtain a M30 grade concrete is in accordance with IS10262- 2009.

\section{Properties}

In this experimental investigation materials used are cement, fine aggregates, coarse aggregates, GGBS, Nano-Silica, Superplasticizer. 


\subsubsection{Cement}

In the Experimental investigation Ordinary Portland cement (OPC) of 53 Grade with a brand name Ultratech is used for all concrete mixes satisfies all the requirements of is122691987.The properties of cement as shown 1 in table 1 .

Table 1: Physical Properties of Cement

\begin{tabular}{|c|c|c|}
\hline Si.No & Properties & Result \\
\hline 1 & Max nominal size & 20 \\
\hline 2 & Bulk Density $(\mathrm{kg} / \mathrm{m} 3)$ & 1565 \\
\hline 3 & Specific Gravity & 2.62 \\
\hline 4 & Fineness modulus & 5.58 \\
\hline
\end{tabular}

\subsubsection{Aggregates}

\section{Fine Aggregates}

Locally available river sand collected from Harihara river was used. The sand confirming to 'zone II' confirming to IS:383:1987. The properties of fine aggregates as shown in table 2 .

Table 2: Physical Properties of Fine Aggregate

\begin{tabular}{|c|c|}
\hline Tests & Results \\
\hline Specific gravity & 3.11 \\
\hline Fineness & $2 \%$ \\
\hline Nomal consistency & $28 \%$ \\
\hline Initial setting time & $34 \mathrm{~min}$ \\
\hline Final setting time & $520 \mathrm{~min}$ \\
\hline
\end{tabular}

\section{Coarse Aggregates}

The crushed stone aggregates was used from the local quarry. In the experimental investigation the aggregates was used 20mm down and tested as per IS:2386:19861 (I,II,III) Specification. The properties of coarse aggregates as shoen in table 3.

Table 3: Physical Properties of Coarse Aggregate

\begin{tabular}{|l|l|l|}
\hline Si No & Properties & Result \\
\hline 1 & Bulk 1Density $(\mathrm{kg} / \mathrm{m} 3)$ & 1689 \\
\hline 2 & Specific1Gravity & 2.50 \\
\hline 3 & Fineness modulus1 & 2.96 \\
\hline
\end{tabular}

\subsubsection{GGBS}

GGBS is extremely fine particle, which exist in white colour powder form. GGBS has procured from ' $J S W$ STEELS', Bellary, Karnataka.
Table 4: Properties of 1GGBS as shown

\begin{tabular}{|c|c|c|}
\hline Si.No & cProperties & Result \\
\hline 1 & Colour & White \\
\hline 2 & Specific Gravity & 2.9 \\
\hline 3 & $\mathrm{Sio}_{2} 1$ & $99.89 \%$ \\
\hline
\end{tabular}

\subsubsection{Nano-Silica(ns)}

Nan-Silica which is obtaine from sisco research laboratories Pvt.Ltd Mumbai, india.

Table 5: Properties of nano-Silica

\begin{tabular}{|c|c|c|}
\hline Si.No & Properties & Result \\
\hline 1 & PH & 23.6 \\
\hline 2 & Specifivc Gravity & $1.08-1.11$ \\
\hline 3 & Particle size & $219 \mathrm{~nm}$ \\
\hline
\end{tabular}

\section{EXPERIMENTAL PROGRAMME}

The experimental programme was designed to compare the mechanical properties i.e compressive strength ,split tensile strength, and flexural strength of High strength concrete with M30 grade of concrete and with different percentage replacement levels of OPC with GGBS $(10 \%, 20 \%, 30 \%)$ and nano-silica $(1 \%, 2 \%, 3 \%)$.

\subsection{PROPORTION}

The concrete mixes was designed to a compressive Strength of M30 grade with water cement ratio 0.45 respectively as per IS 10262:2009. In both the cases cement is replaced with GGBS by $(10 \%, 20 \%, 30 \%)$ and Nano-Silica by $(1 \%, 2 \%, 3 \%)$ The proportions of constituent materials for mixes are Presented in table 6.

Table 6: Proportions of constituent material

\begin{tabular}{|c|c|c|}
\hline Si.No & Material & Quantities in $\mathrm{Kg} / \mathrm{m}^{3}$ \\
\cline { 3 - 3 } & & $\mathrm{M}_{30}$ Grade \\
\hline 1 & Cement & 2425.733 \\
\hline 2 & Water & 2192 \\
\hline 3 & Fine Aggregate & 2772.8 \\
\hline 4 & Coarse Aggregate & 2950.74 \\
\hline 5 & Water cement ratio & 20.45 \\
\hline
\end{tabular}

\subsection{Experimental Results and Discussions}

\subsubsection{Compressive Strength Test}

Following tables gives the compressive strength test results of concrete produced by replacing cement by GGBS and Nanosilica in different percentages.

\subsubsection{General Effect of Nano Silica}

With 0\% nano silica the basic M30 concrete has the design strength of $39.68 \mathrm{MPa}$ at 28 days and with $1 \%$ nano silica the strength has gone up to $42.20 \mathrm{MPa}$. There is gradual increase in compressive strength up to $2 \%$ where the value 
is $45.56 \mathrm{MPa}$. Thus there is an increase of 5.88 MPa which is equal to nearly $8 \%$. Beyond $2 \%$ nano silica, the strength is coming down and the recorded value is $41.30 \mathrm{MPa}$ for $3 \%$ nano silica. Hence, $2 \%$ nano silica appears to be the optimum in present experimental study.

\subsubsection{Effect of $\mathrm{nS}$ and GGBS on the Compressive}

\section{Strength}

From the graph it is observed that increase the strength properties of concrete combination of nano silica with GGBS is tried in the present experimental work. With $0 \%$ nano silica and $0 \%$ GGBS the basic M30 concrete has given design strength of $39.68 \mathrm{MPa}$ at 28 days, with $2 \%$ nanosilica and 0\% GGBS6the strength is going up to 45.56 MPa. Similarly with 0\% nanosilica and 30\% GGBS the strength is $41.64 \mathrm{Mpa}$. In the same way with $2 \%$ nano silica and $30 \%$ GGBS the strength is further going up to $48.926 \mathrm{MPa}$. Hence, out of all the combinations the highest strength is obtained with $2 \%$ nano silica6and $30 \%$ GGBS in the present study. This is due to nanosilica fills the pores6in the concrete both nanosilica and ggbs involves in the pozzolanic reaction with $\mathrm{C}-\mathrm{H}$ and forms stable $\mathrm{C}-\mathrm{S}-\mathrm{H}$ bond between the matrix and the aggregates thus reducing the porosity and makes concrete dense which in turn increases compressive strength of concrete.

\subsubsection{Flexural Strength Results}

With $0 \%$ nano silica and $0 \%$ GGBS the basic M30 concrete has given design strength of $3.81 \mathrm{MPa}$ at 286days. With $2 \%$ nanosilica and 0\% GGBS the strength is going upto 4.45 MPa and with 2\% Nano Silica and 30\% GGBS the strength is further going upto $4.63 \mathrm{MPa}$. Hence, out of these combinations, the highest strength with $2 \%$ nano silica and $30 \%$ GGBS is obtained in the present study. This is due to nanosilica fills all the pores both nanosilica and ggbs involves in the pozzolanic reaction with $\mathrm{C}-\mathrm{H}$ and forms stable $\mathrm{C}-\mathrm{S}-\mathrm{H}$ bond between the matrix and the aggregates thus reducing the porosity which in turn increases in the Flexural strength of concrete.

\subsubsection{Split Tensile Strength Results}

With $0 \%$ nano silica and $0 \%$ GGBS the basic M30 concrete has given design strength of $2.86 \mathrm{MPa}$ at 28 days. With $2 \%$ nanosilica and $0 \%$ GGBS the strength is going upto 4.25MPa and with $2 \%$ nano silica and $30 \%$ GGBS the strength is further going upto $4.38 \mathrm{MPa}$. Hence out of all the combinations, the highest strength with $2 \%$ nano silica and $30 \%$ GGBS is obtained. This is due to nano silica fills the pores in the concrete both nanosilica and ggbs involves in the pozzolanic reaction with $\mathrm{C}-\mathrm{H}$ and forms stable $\mathrm{C}-\mathrm{S}-\mathrm{H}$ bond between the matrix and the aggregates thus reducing the porosity and makes concrete dense which in turn increases the tensile strength of concrete.
Table 7: Shows compressive strength of concrete atm 7 and 28 days

\begin{tabular}{|c|c|c|c|c|}
\hline \multirow{2}{*}{ Si.No } & \multirow{2}{*}{ \%GGBS } & \multirow{2}{*}{$\begin{array}{c}\text { \%Nano- } \\
\text { Silica }\end{array}$} & \multicolumn{2}{|c|}{$\begin{array}{c}\text { Compressive } \\
\text { strength in N/mm }\end{array}$} \\
\cline { 4 - 5 } & & & \multicolumn{2}{|c|}{$\mathbf{M}_{\mathbf{3 0}}$ Grade } \\
\cline { 4 - 5 } & & 0 & 22.123 & 39.68 \\
\hline 1 & 0 & 0 & 20.52 & 38.20 \\
\hline 2 & 10 & 0 & 21.48 & 39.92 \\
\hline 3 & 20 & 0 & 21.96 & 41.64 \\
\hline 4 & 30 & 1 & 23.52 & 42.20 \\
\hline 5 & 0 & 2 & 26.45 & 45.56 \\
\hline 6 & 0 & 3 & 21.74 & 41.30 \\
\hline 7 & 0 & 2 & 29.37 & 48.92 \\
\hline 8 & 30 & & & \\
\hline
\end{tabular}

Table 8: Shows Split tensile strength of concrete at 7 and 28 days

\begin{tabular}{|c|c|c|c|c|}
\hline \multirow{2}{*}{ Si.No } & \multirow{2}{*}{ \% GGBS } & \multirow{2}{*}{$\begin{array}{c}\text { \% Nano- } \\
\text { Silica }\end{array}$} & \multicolumn{2}{|c|}{$\begin{array}{c}\text { Split Tensile } \\
\text { strength in } \\
\text { N/mm }\end{array}$} \\
\cline { 4 - 5 } & & & \multicolumn{2}{|c|}{$\mathbf{M}_{\mathbf{3 0}}$ Grade } \\
\cline { 4 - 5 } & & 0 & 22.123 & 39.68 \\
\hline 1 & 0 & 0 & 20.52 & 38.20 \\
\hline 2 & 10 & 0 & 21.48 & 39.92 \\
\hline 3 & 20 & 0 & 21.96 & 41.64 \\
\hline 4 & 30 & 1 & 23.52 & 42.20 \\
\hline 5 & 0 & 2 & 26.45 & 45.56 \\
\hline 6 & 0 & 3 & 21.74 & 41.30 \\
\hline 7 & 0 & 2 & 29.37 & 48.92 \\
\hline 8 & 30 & & & \\
\hline
\end{tabular}

Table 9: Shows Flexural Strength of Concrete at 28 days

\begin{tabular}{|c|c|c|c|}
\hline \multirow{2}{*}{ Si.No } & \multirow{2}{*}{$\%$ GGBS } & \multirow{2}{*}{$\begin{array}{c}\text { Flexural } \\
\text { Strength } \\
\text { In N/mm }\end{array}$} \\
\cline { 4 - 4 } & & & $\mathbf{M}_{\mathbf{3 0}}$ Grade \\
\cline { 4 - 4 } & & 0 & $\mathbf{2 8}$ days \\
\hline 1 & 0 & 0 & 3.81 \\
\hline 2 & 30 & 2 & 4.45 \\
\hline 3 & 0 & 2 & 4.16 \\
\hline 4 & 30 & & 4.63 \\
\hline
\end{tabular}



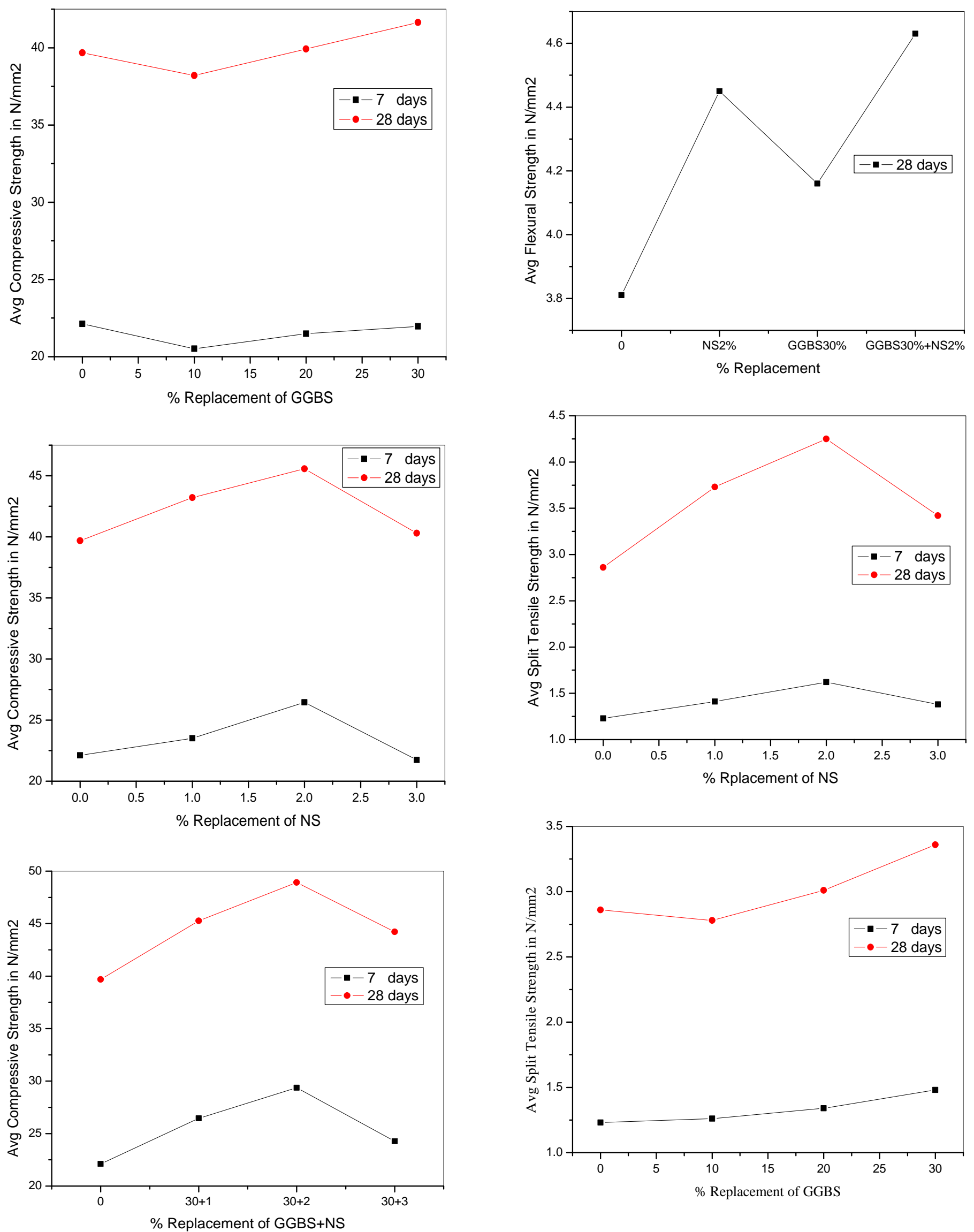


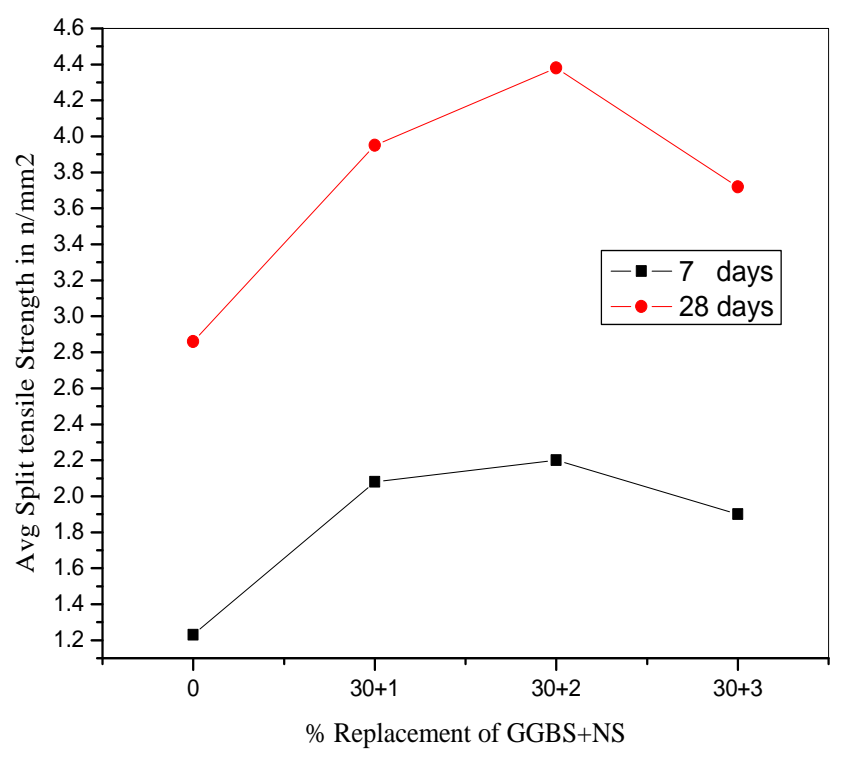

\section{CONCLUSION}

1. A well planned experimental research work has been carried out to understand the behaviour of GGBS and nano silica on strength properties of concrete. Major conclusions drawn from these studies have been presented here.

2. Cement replacement upto $30 \%$ with GGBS and upto $2 \%$ NS leads to increasing compressive strength and split tensile strength. Beyond that there is decreasing in compressive strength and split tensile strength.

3. Maximum replacement level of GGBS is $30 \%$ and NS is $2 \%$ for M30 grade concrete.

4. Nano silica addition decreases the initial and final setting time of mix when added $2 \%$ by weight of cement as it contributes to increased $\mathrm{CH}$ production of early age.

5. The Portland cement in concrete releases calcium hydroxide during the hydration process. The nano silica and GGBS reacts with the calcium hydroxide to form additional binder material.

6. The availability of additional binder leads to increase in the paste-aggregate bond, results improved strength properties of the concrete prepared with nano-silica and ggbs combination.

7. The above discussions described that the influence of NS along with cement, GGBS considerable improvement in the properties such as rheological behavior of concrete, heat of hydration, the pozzolanic activity8or reactions and workability, strength and durability were reported.

8. The SEM test shows that microstructure of nano Sio2 concrete is more uniform and compact than the normal concrete.

9. The pore structure of concrete containing nano particles is improved and the content of all mesopores and macropores is decreased.

10. To avoid the agglomeration effect, this study suggests the percentage of nanosilica in the concrete to be not more than $2 \%$.

\section{REFERENCES}

[1] Feldman R.F., Sereda P.J(1968)., A model for hydrated Portland cement paste as deduced from absorptionlength change and mechanical properties, Materials and Structures, 6, 509-519.

[2] Bjornstrom J., MartinelliA., (2004), Accelerating effects of colloidal nano-silica for beneficial calciumsilicate-hydrate formation in cement, Chemical Physics Letters, vol-392, pp-242-248.

[3] Ye Qing, Zenan Z., Deyu K. and Ch. Rongshen,( (2007), Influence of nano-SiO2 addition on `f hardened cement paste as compared with silica fume, Constr. Build Mater., 21, 539-545.

[4] Jo Byung-Wan, Kim Chang-Hyun, and Lim Jae-Hoon,( (2007), Characteristics of cement mortar with nanoSiO2 particles, ACI Mat. Jl., 104(4), 404-407.

[5] Gaitero J.J., Campillo I. and Guerrero A.,( (2008), Reduction of the calcium leaching rate of cement paste by addition of silica nano particles, Cem. and Con. Res., 38, 1112-1118.

[6] M.Nili, A.Ehsani, and K.Shabani (2009), "Influence of Nano Si02 and micro silica on concrete performance " Bu-Ali Sina University.

[7] Surya Abdul Rashid et.al.,(2010),"Experimental investigation of the size effect of $\mathrm{SiO} 2$ nano particles on Mechanical properties of binary blended concrete" Composites (part-B) Vol-41,pp 673-677.

[8] M.Collepardi, J.J.Ogoumah et.al.,( 2010), "Combination of Silica fume, fly ash, and amorphous Nano silica in super plasticized HPC "Engineering concrete research.

[9] Ali-Nazari et.al.,( Feb2011), "SiO2 Nano particles effects on physical, thermal and Mechanical properties of SCC with GGBFS as binder "-Energy and buildings -vol-43 pp 995-1002.

[10] Ali Heidari, Davoud Tavakoli (Sept 2012), “A Study of Mechanical properties of ground ceramic powder concrete incorporating nano Si02 particles" Construction and Building Materials -Vol. 38 , pp 255264.

[11] Min-Hong Zhang, Jahidul Islam et.al.,( Feb 2012), “ Use of Nano-Silica to increase early strength and reduce setting time of concrete with high volume slag" -Cement and concrete composites-Vol -34 -pp 650662.

[12] Jonbi, Ivindra Pane Binsar, Hariandja, IswandiImran (2012)., The Use of Nanosilica for Improving of Concrete Compressive Strength and Durability. Applied Mechanics and Materials Vols. 204-208 (2012) pp 4059-4062 .

[13] Mohammad Reza Zamani Abyaneh et.al.,(2013), "Effects of Nano-Silica on Permeability of Concrete and Steel Bars Reinforcement Corrosion" Australian Journal of Basic and Applied Sciences, 7(2): 464-467, 2013 ISSN 1991-8178.

[14] Kartikeyan.B, K. Sumanth, G. Harshavardhan,A. Rajasekharareddy and G.Dhinakaran(2014), Microstructure analysis and Strength properties of concrete with Nano SiO2 Vol.6, No.5, pp 3004-3013,.

[15] Kaura.J.M, A. Lawan, I. Abubakar and A. Ibrahim 
(2014), Effect of Nanosilica on Mechanical and Microstructural Properties of Cement Mortar Volume 8, No. 2,.

[16] Mukharjee.B.B and S.V. Barai (2014), Characteristics of Mortars Containing Colloidal Nano-Silica Volume 9,pp. 17-22@ Research India Publications.

[17] PrasadaRao.D.V, M. Pavan Kumar(2014).,:A Study On Influence Of Fly Ash And Nano- Silica On strength Properties Of Concrete Volume 5, Issue 7, pp. 94-102.

[18] Rathi.V.R, Dr.C.D.Modhera (2014), An overview on the Influence of Nano Materials on Properties of ConcreteVol. 3, Issue 2. 